\title{
INCIDENCE OF SALMONELLAE IN CHILLED CHICKEN CARCASSES IN RETAILS PORT-SAID CITY
}

\author{
NAHLA T. KORASHY ${ }^{*}$ and GIHAN M.O. MOHAMMED ${ }^{* *}$ \\ * Microbiology department, Port-Said Lab., animal health research institute, Dokki, Giza, Egypt. \\ ${ }^{* *}$ Microbiology department, Port-Said Lab., animal health research institute, Dokki, Giza, Egypt.
}

\begin{abstract}
Received at: 14/6/2012

Accepted: 8/7/2012

A total of 120 samples were collected from retail markets from November 2011 to February 2012. Salmonella spp. was detected in $14(11.7 \%)$ of the samples analyzed. Among the chicken samples examined giblets had higher contamination level of Salmonella 7 (5.8\%) while the meat samples had lower percent of contamination $3(2.5 \%)$. Out of 14 Salmonella isolates, 5 different serotypes were identified $S$. typhimurium (42.9) was the most frequent followed by $S$. enteritidis $21.4 \%$, S. virchow $21.4 \%$, S.anatum $7.1 \%$ and Salmonella type $\Pi 7.1 \%$. The results of the present study indicated that there was a high level of Salmonella contamination of chicken meat and giblets in retail markets, which could be considered as one of the major potential source of human salmonellosis in PortSaid, city.
\end{abstract}

Key words: Salmonella, chilled chicken, Port-Said City.

\section{INTRODUCTION}

Poultry meat constitutes a substantial portion of protein in the present day diets, hence it has an important share $(30 \%)$ in the world's total meat consumption (Del Rio et al., 2007). Poultry meat can be contaminated with a variety of foodborne pathogens (Mor-Mur and Yuste, 2010). The presence of pathogenic microorganisms, spoilage microorganisms or both in Poultry is undesirable but unavoidable (Goncalves et al., 2004). Salmonellosis is an important global public health problem causing substantial morbidity, and thus also has a significant economic impact. In spite of the improvement in hygiene, food processing, education of food handlers and information to the consumers, foodborne diseases still dominate as the most important public health problem in most countries. Dominguez et al. (2002).

Poultry meat and its derivatives are among the food products that cause the most concern to public health authorities, owing to the associated risks of bacterial food poisoning. The modernization of chicken farms and globalization of the bird breeding trade also have played a role in infection. Velge et al. (2005).

In humans, Salmonella is the cause of two diseases called salmonellosis: enteric fever (typhoid), resulting from bacterial invasion of the blood stream, and acute gastroenteritis, resulting from a foodborne infection/intoxication. It has been reported that 10$20 \%$ of Salmonellosis outbreaks were related to poultry meat consumption (Bailey, 2002). Most people infected with Salmonella develop diarrhea, fever, and abdominal cramps 6 to 72 hours after infection. In most cases, the illness usually lasts 3 to
7 days - most affected people recover without treatment. However, in some people the diarrhea may be so severe that the patient becomes dangerously dehydrated and must be taken to a hospital.

Poultry and poultry products are usually incriminated in outbreaks of human salmonellosis. Salmonella often reach the carcasses from the intestinal tracts or faecal materials on feathers or feet. Particularly scalding, defeathering, evisceration and giblet operations are the major points of spread in poultry processing plants (Bryan and Doyle, 1995), (D'aoust, 1989) and Uyttendaele et al. (1998).

The cross-contamination of hands of workers, working equipment and utensils could also serve as a mean of spread of Salmonella to uncontaminated carcasses and giblets in which contamination could continue during subsequent handling, processing and preparations. (Scott, 1996) and Uyttendaele et al. (1998).

Previous works undertaken in Egypt indicated the presence and distribution of Salmonella in wild birds (Azza, 2003), poultry farms (El-Jakee et al., 2010), laying farms (Mona, 2007), calves (Moussa et al., 2010), House sparrows and Laughing doves (Helal, 2007) poultry meat and meat products (Raafat et al., 2011) man (Weal et al., 2011). Various serotypes of Salmonella were also identified from House sparrows and Laughing doves, calves, poultry meat and man in Egypt (Helal, 2007; Moussa et al., 2010, Raafat et al., 2011 and Weal et al., 2011).

A periodic surveillance of the level of Salmonella contamination in the different food animals, food products and environment is necessary to control the 
spread of the pathogen and infection of man (Arumugaswamy et al., 1995 and Dawson, 1992). The knowledge on the prevalent Salmonella serotypes in a country is also important in order to understand the distribution and means of introduction into a country Jegathesan (1984). This study was, therefore, undertaken to determine the prevalence and distribution of serotypes of Salmonella in chilled chicken carcass obtained from retails Port-Said city.

\section{MATERIALS and METHODS}

\section{1-Sampling:}

One hundred and twenty samples of each chilled chicken carcass (40 meat, 40 giblets and 40 drip) were randomly collected from different retails in Port- Said city. Each sample was obtained aseptically and transported in iceboxes packed with ice to laboratory as soon as possible to be subjected to bacteriological examinations.

\section{2- Isolation and identification of Salmonella:}

Salmonellae were isolated and identified according to the techniques recommended by the International Organisation for Standardisation (ISO, 2002).

\section{2-1- Pre-enrichment in non selective medium:}

Briefly, $25 \mathrm{~g}$ of each sample of meat and giblet was weighed and cut into smaller fine pieces with sterile scalpel blades. Each sample was put in a sterile stomacher bag and $225 \mathrm{ml}$ of buffered peptone water (BPW; Difco, USA) was added, homogenized using a stomacher. In case of drip samples, pre-enriched in BPW in a ratio of $1 \mathrm{ml}$ of the sample to $9 \mathrm{ml}$ of BPW. The pre-enriched Samples were incubated for 16 to 20 hours at $37^{\circ} \mathrm{C}$.

\section{2-2- Selective enrichment:}

One $\mathrm{ml}$ and $0.1 \mathrm{ml}$ of the pre-enrichment broth was transferred aseptically into each of $10 \mathrm{ml}$ of Mauller Kouffmann Tetrathionate novobiocin broth (Difco, Detroit, USA) and $10 \mathrm{ml}$ of Rappaport Vassiliadis soy broth (RVS; Oxoid) and incubated for 18 to 24 hours at $37^{\circ} \mathrm{C}$ and $42^{\circ} \mathrm{C}$ respectively.

\section{2-3-Plating out on selective agar media:}

Each enrichment culture was streaked on two selective agar media, xylose lysine deoxycholate agar (XLD; Oxoid) and Hektoen enteric agar (HE; Difco)and incubated at $37^{\circ} \mathrm{C}$ for 18 to 24 hours.

\section{2-4- Selection of colonies for purification:}

From each selective media plate, at least one colony considered being typical or suspect was picked and streaked onto the surface of nutrient agar plate for further identification.

\section{2-5- Identification of the isolates:}

2-5-1- Microscopical identification of the isolates: Smears from the purified colonies wear prepared and stained with Gram's stain method and examined microscopically for the morphological character of salmonella according to (Quinn et al., 2002 ).

\section{2-5-2-Biochemical identification:}

Salmonella spp. isolates were identified biochemical by Triple sugar iron agar, Lysine iron agar, and urea then by Microbact-12A test kit.

\section{2-5-3- Serotyping of salmonella isolates:}

Colonies with biochemistry profile of Salmonella were serologically confirmed using diagnostic polyvalent $(\mathrm{O}, \mathrm{H})$ and monovalent Salmonella antisera. Suspected salmonella were cultured on TS agar slants for $24 \mathrm{~h}$ at $37^{\circ} \mathrm{C}$. A loopfull from the culture was suspended in drop of phosphate buffer saline $(\mathrm{pH}$ 7.4) on a slide to make a homogenous suspension and then a drop of Salmonella anti-sera was added to the suspension and thoroughly mixed to bring the organisms in close contact with anti-sera. Positive agglutination occurred with in a minute. A delayed or partial agglutination was considered as negative or false reaction. (Kauffmann and Das- Kauffmann 2001)

\section{RESULTS}

Of the total of 120 samples examined, $11.7 \%$ were contaminated with salmonellae (Table 1). A high level of salmonella contamination was found in giblet $(5.8 \%)$ followed by drip (3.3\%) and meat $(2.5 \%)$.

Table 1: Prevalence of Salmonella isolated from chilled chicken carcasses.

\begin{tabular}{lccccc}
\hline \multirow{2}{*}{$\begin{array}{l}\text { Type of samples } \\
\text { (no.) }\end{array}$} & No. of samples & \multicolumn{3}{c}{ prevalence of Salmonella } \\
\cline { 3 - 6 } & & \multicolumn{2}{c}{ Negative } & \multicolumn{2}{c}{ Positive } \\
\cline { 3 - 6 } Meat & 40 & 36 & 27.5 & 7 & 5.8 \\
\hline Giblet & 40 & 37 & 30.8 & 4 & 3.3 \\
\hline Drip & 40 & 106 & 88.3 & 14 & 11.7 \\
\hline Total & 120 & & & & \\
\hline
\end{tabular}

Out of the total 14 salmonella isolates, 5 different serotypes were identified of which $S$. Typhimurium 42.9 was the most frequent followed by $S$. virchow $21.4 \%$, S. enteritidis $21.3 \%$, S.anatum $7.1 \%$ and Salmonella type $\Pi$ 7.1\%. (Table 2). S.Typhimurium and S. enteritidis were isolated from all sample types (chicken meat, giblets and drip) while other serotypes isolated from giblets and drip. Most of the isolates belonged to the sero-group B. $(42.9 \%)$ while the lowest number of the isolates belonged to sero-group E1 and type П. (Table 3) 
$\underline{\text { Assiut Vet. Med. J. Vol. } 58 \text { No. } 134 \text { July } 2012}$

Table 2: Prevalence of different Salmonella serovars recovered different samples.

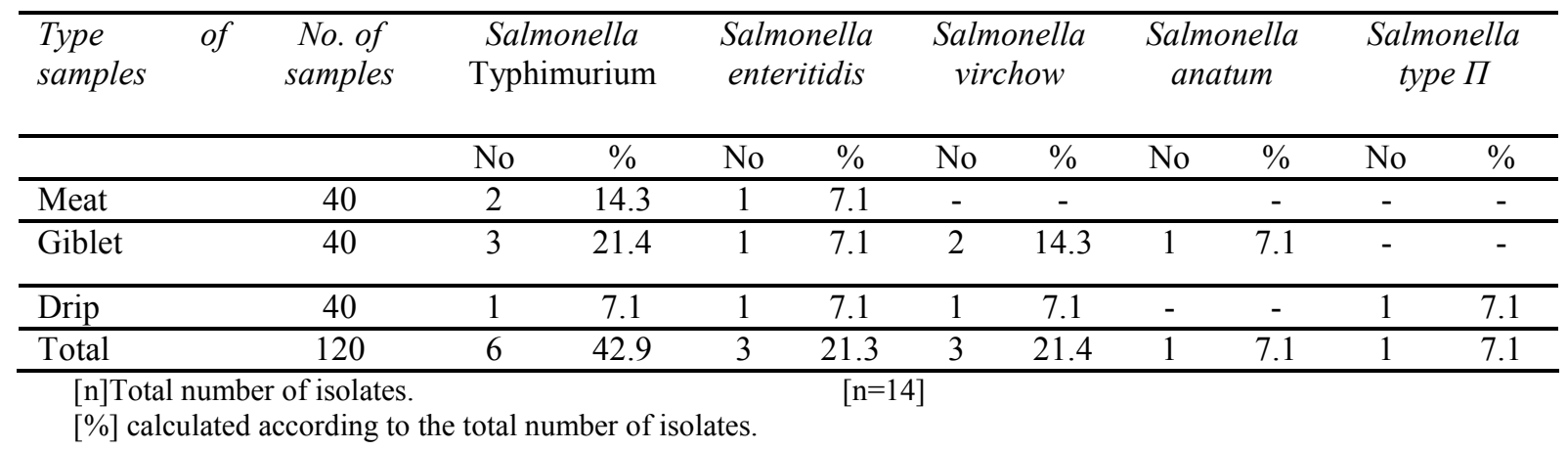

Table 3: Antigenic formula of the isolated serovar.

\begin{tabular}{|c|c|c|c|c|c|}
\hline \multirow[t]{3}{*}{ Salmonella serovars } & \multirow{3}{*}{$\begin{array}{l}\text { No of } \\
\text { strain }\end{array}$} & \multirow{3}{*}{$\begin{array}{l}\text { Sero- } \\
\text { group }\end{array}$} & \multicolumn{3}{|c|}{ Antigenic structure } \\
\hline & & & \multirow[t]{2}{*}[\mathrm{O}]{} & \multicolumn{2}{|c|}{$[\mathrm{H}]$} \\
\hline & & & & Phase (1) & Phase(2) \\
\hline Salmonella Typhimurium & 6 & $\mathrm{~B}$ & $1,4,[5], 12$ & $\mathrm{i}$ & 1,2 \\
\hline Salmonella enteritidis & 3 & D1 & 9 & $\mathrm{~g}, \mathrm{~m}$ & ------ \\
\hline Salmonella anatum & 1 & E1 & $3,10[15][15,34]$ & $\mathrm{e}, \mathrm{h}$ & 1,6 \\
\hline Salmonella virchow & 3 & $\mathrm{C} 1$ & $6,7,14$ & $\mathrm{r}$ & 1,2 \\
\hline Salmonella type $\Pi$ & 1 & type $\Pi$ & 6,7 & $\mathrm{~g}, \mathrm{~m}, \mathrm{~s}, \mathrm{t}$ & ------ \\
\hline
\end{tabular}

\section{DISCUSSION}

Among the foodborne pathogens the genus Salmonella is one of the most common causes of foodborne infections worldwide (Baird-Parker, 1990). Characteristic feature of this organism is its wide host range, which comprises most animal species including mammals, birds and cold-blooded animals in addition to humans. It has been reported that Salmonella is one of the most important pathogens responsible for human food poisoning in the developed world, and chicken products are widely acknowledged to be a significant reservoir for Salmonella. Therefore, this organism has been isolated from a range of foods in almost every country in which it has been investigated Rajashekara et al. (2000). Chickens are commonly infected with a wide variety of salmonella serovars. Infections are generally sub-clinical and one serovar may be a predominant isolate in a country for several years before it replaced by another serovar (Wray et al., 1996). Bacteriological examination is the traditional mean to obtain accurate data about the prevalence of infected host of salmonellae (Commission of the European Communities, 1992).

In the present study, a total number of 120 chicken samples representing (40 meats, 40 giblet and 40 drip) were collected from different retails in port-said city for bacteriologically and serologically examination to detect the presence of salmonella species.

The level of Salmonella contamination of chilled chicken carcasses observed in our study $(11.7 \%)$ was relatively high and confirms the findings of previous studies on Salmonella contamination in poultry and poultry products in Egypt (El-Jakee et al., 2010; Raafat et al., 2011).

A number of authors in different countries have reported different prevalence rates of Salmonella in poultry and poultry products $21.1 \%$ in Ethiopia (Molla and Mesfin 2003), $22.8 \%$ in UK (Plummer et al. 1995), $35.5 \%$ in Malaysia (Rusul et al., 1996), $35.8 \%$ in Spain (Dominguez et al., 2002) and 36.7\% in Belgium Uyttendaele et al. (1998).

The variation in the prevalence of Salmonella contamination could be partly due to differences in sample type, sampling techniques, distribution of salmonellae in a lot examined and the detection methods employed (Bryan and Doyle 1995; Dominguez et al., 2002; Rusul et al., 1996 and Uyttendaele et al., 1998).

In the present study out of the total 120 samples 40 were giblets (liver, heart and gizzard) had higher contamination level of Salmonella $(5.8 \%)$ while the meat samples had lower percent of contamination $2.5 \%$. (Table 1). This was in agreement with the findings of (Jerngklinchan et al., 1994; Molla et al., 1999 and Boniphace 2001) who reported that prevalence rates of Salmonella in chicken giblets more than of the carcass samples.

On the other hand a high level of Salmonella contamination was detected in retail chicken meat and giblets (Arumugaswamy et al., 1995; Rusul et al., 1996 and Carraminana et al., 1997).

Cross-contamination of Salmonella from giblets to carcass could occur during handling, processing, 
packing and distribution. The packing of giblets with the carcass observed in this study at processing plants could have also contributed to increase Salmonella cross-contamination. In addition to these, scalding water can become contaminated with Salmonella from faeces, plucking equipment, cages and floors. Workers can spread the contamination during retailing (Arumugaswamy et al., 1995 and Uyttendaele et al., 1998). Rupture of the intestine could also occur during evisceration and pooling giblets might lead to cross-contamination of carcasses and other chicken parts.

Out of the total 14 Salmonella isolates, 5 different Salmonella serotypes were identified (Table 2). The most prevalent serotypes were $S$. Typhimurium, followed by $S$. virchow and $S$. enteritidis. Our results come in agreement with Wafaa et al. (2012) who reported that $S$. Typhimurium and $S$. enteritidis were the most prevalent serotypes isolated from diseased and apparently healthy broiler chicken flocks in Egypt.

Other researchers have reported some of these serotypes in poultry meat and poultry products Carraminana et al. (1997); (Boniphace, 2001); Molla and Mesfin (2003). It should also be noted that the presence and distribution of Salmonella serotypes could vary from region to region (Uyttendaele et al., 1998 and Dominguez et al., 2002). While some serotypes emerge and decrease over time, others maintain their dominant role for many years with widespread distribution. The rapid international trade in agricultural, aquacultural and food products has also facilitated the introduction of new Salmonella serotypes into importing countries (D'aoust, 1994).

The high prevalence of $S$. Typhimurium observed in the present study reflects the presence of this serovar in the intestinal tract of live broilers, contaminating carcasses during slaughter and processing.

This study on poultry meat sale points revealed that most of the retails do not operate in a safe and clean environment, and rarely practice the appropriate covering for displayed carcass. Moreover, the isolation of different Salmonella sero-groups B (42.9\%), D1 and C1 (21.3\%) and (21.4\%), E1 and type $\Pi(7.1 \%)$ were identified. (Table 3$)$

These indicate the presence and distribution of various serotypes of Salmonella of animal and human origin, which are of significance in the veterinary and public health sectors in Port-said city. The isolation of invasive Salmonella serotypes such as $S$. Typhimurium and other pathogenic salmonella in our study indicates the public health significance of these serovars as contaminated chicken meat and meat products may pose health hazards. This risk may further be higher if chicken meat or giblets are consumed undercooked or cross-contamination in the kitchen with Salmonella during meal preparation (Scott, 1996 and Uyttendaele et al., 1998). The risk increases if the drip contains salmonella which may reach to the consumer due to improper handling of these products. The importance of some of the basic instructions regarding storage temperature, cooking and prevention of Salmonella contamination and cross-contamination is not appreciated by many consumers (Scott, 1996 and Uyttendaele et al., 1998). Therefore, efforts should be made to enhance public awareness and consumer education to prevent the horizontal spread of Salmonella. Some of the measures in controlling Salmonella and other foodborne pathogens in the food chain include the introduction of good manufacturing practices (GMP) and hazard analysis critical control point (HACCP) concepts together with stringent control of all aspects of chicken meat production, preparation and distribution (Dawson, 1992). Education of personnel involved in food preparation and microbiological monitoring of broiler chicken and rejection of infected flocks from food production is also required (Arumugaswamy et al., 1995). The high level of contamination of chicken meat and giblets with Salmonella observed in our study indicates the need for an improvement in the microbiological quality of retail chicken. There is also a need for a comprehensive epidemiological study and control of Salmonella contamination at various levels of chicken production and processing plants in Egypt.

It could be concluded that there are different Salmonella serotypes including $S$. typhimurium, S. enteritidis, S.virchow, S. anatum and Salmonella type $\Pi$ circulating in broiler chicken farms in Port said city, Egypt and the most prevalent ones are S.Typhimurium and S.enteritidis. The prevalence of both Salmonella serotypes in our broiler chicken farms constitutes an important problem due to their zoonotic importance and consequently the adverse effect on the human health.

Foodborne illness usually arises from improper handling, preparation, or food storage. Good hygiene practices before, during, and after food preparation can reduce the chances of contracting an illness. There is a consensus in the public health community that regular hand-washing is one of the most effective defenses against the spread of foodborne illness.

\section{REFERENCES}

Arumugaswamy, R.K.; Rusul, G.; Abdul hamid, S.N. and Chaeh, C.T. (1995): Prevalence of Salmonella in raw and cooked foods in Malaysia. Food Microbiol, 12: 3-8.

Azza, S.A.G. (2003): Prevalence and characterization of salmonella strains isolates from wild birds. Ph.D. thesis, faculty of veterinary medicine Suez Canal University.

Bailey, J.S. (2002): Advances and challenges in the control of Salmonella in poultry. Food safety Magazine,8(5), 18-23.

Baird-Parker, A.C. (1990):Foodborne Salmonellosis. Lancet; 336: 1231-1235. 
Boniphace, J.T. (2001): Cross-sectional study of Salmonella in chicken meat and offals in Addis Ababa, Ethiopia. Addis Ababa University and Freie Universität Berlin, MSc thesis.

Bryan, F.L. and Doyle, M.P. (1995): Health risks and consequences of Salmonella and Campylobacter jejuni in raw poultry. J Food Prot; 58: 326-3440.

Carraminana, J.J.; Yanguela, J.; Blanco, D.; Rota, C.; Agustin, A.I.; Arino, A. and Herrera, A. (1997): Salmonella incidence and distribution of serotypes throughout processing in a Spanish poultry slaughterhouse. J. Food Prot., 60: 1312-1317.

Commission of the European Communities (1992): Concerning means for protection against specified zoonotic agents in animals and product of animal origin in order to prevent outbreaks of food borne infections and intoxication. Council Directorate 92/117/EEC.

Dawson, P.S. (1992): Control of Salmonella in poultry in Great Britain. Int. J. Food Microbiol., 15: 215-217.

D'aoust, J.Y. (1989): Salmonella. In: DOYLE M.P. (ed.): Foodborne Bacterial Pathogens. Marcel Dekker Inc., NewYork, 327-445.

D'aoust, J.Y. (1994): Salmonella and the international food trade. Int. J. Food Microbiol, 241: 11-31.

Del Rio, E.; Panizo, M.M.; Prieto, M.; AlonsoCalleja, C. and Capita, R. (2007): Effects of various chemical decontamination on natural flora and sensory characteristics of poultry. International Journal of Food Microbiology, 115: 268-280.

Dominguez, C.; Gomenz, I. and Zumalacarregui, J. (2002): Prevalence of salmonella and Campylobacter in retail outlet in Spain. Internationa J. Food Microbiol., 72(1): 165-168.

El-Jakee, J.; Sherein, A.E.; Mohamed, K.F.; Effat, M.M.; Samy, A.A. and Gad, El-said, W.A. (2010): Restriction enzyme, plasmid profile analysis and antibiotic resistance of Salmonella Typhimurium of poultry origin isolated from Egyptian farms. International Journal of Microbiological Research 1 (3): 137-146.

Goncalves, A.C.; Almida, R.C.C.; Alves, M.A.O. and Almeida, P.F. (2004): Quantitative investigation on the effects of chemical treatments in reducing Listeria monocytogenes populations on chicken breast meat. Food control in press.

Helal, I.M. (2007): Possible role of house sparrows and laughing doves in transmission of salmonella infection to chickens. Ph.D. thesis, faculty of veterinary medicine - Suez Canal University.

ISO 6579 (2002): (E) $4^{\text {th }}$ ed. Microbiology -General guidance on methods for the detection of
Salmonella. International Organization for Standardization, Geneve, Switzerland

Jegathesan, M. (1984): Salmonella isolated from man in Malaysia over the 10-year period 19731982. J. Hyg. Camb., 92: 395-399.

Jerngklinchan, J.; Koowatanukul, C.; Daengprom, K. and Sattanu, K. (1994): Occurrence of salmonellae in raw broilers and their products in Thailand. J. Food Prot., 57: 808-810.

Kauffmann, F. and Das-Kauffmann, W. (2001): Antigenic formulas of Salmonella serovars WHO co-operating center for reference and research on Salmonella.8 ed, cited by Popoff, M.Y., paris, France.

Molla, B. and Mesfin, A. (2003): A survey of Salmonella contamination in chicken carcass and giblets in Central Ethiopia Revue Med. Vét. 154 (4): 267-270.

Mor-Mur, M. and Yuste, J. (2010): Emerging bacterial pathogens in meat and poultry: an overview. Food Bioprocess Technology, 3: 24-35.

Mona, A.A. (2007): Isolation, identification and characterization of salmonella from laying farm. M.D. Thesis, faculty of veterinary medicine -Cairo University.

Molla, B.; Kleer, J. and Sinell, H.-J. (1999): Occurrence, distribution and level of Salmonella in selected food items in Addis Ababa (Ethiopia). Fleischwirtsch. Int., 4: 37-39.

Moussa, I. M.; Ashgan, M.H.; Mohamed, K.H.F. and Al-Doss, A.A. (2010): Rapid detection of Salmonella species in newborne calves by polymerase chain reaction. International Journal of Genetics and Molecular Biology Vol. 2 (4), pp: 062-066.

Plummer, R.A.S.; Blissett, S.T. and Dodd, C.E.R. (1995): Salmonella contamination of retail chicken products sold in the UK. J. Food Prot., 58: 843-846.

Quinn, P.J.; Carter, M.E.; Markey, B.K.; Donnoly, W.J.; Leonard, F.C. and Maguire, D. (2002): Veterinary microbiology and microbial disease.166-1117. Osney Mead, Oxford first published, Blackwell Science. LTD, Registered at the United Kingdom.

Raafat, H.; Sohaila, F.H.; Ali, Ashraf, M.M.; Moemen, A. and Elsayh, K.I. (2011): Detection and identification of Salmonella species in minced beef and chicken meats by using Multiplex PCR in Assiut city. Vet. World, 4(1): 5-11.

Rajashekara, G.; Harverly, E.; Halvorson, D.A.; Ferris, K.E.; Lauer, D.C. and Nagaraja, K.V. (2000): Multidrug resistant Salmonella Typhimurium DT104 in poultry. J. Food Prot., 63: 155-161.

Rusul, G.; Khair, J.; Radu, S.; Chaeh, C.T. and Yassin, R.Md. (1996): Prevalence of Salmonella in broilers at retail outlets, 
processing plants and farms in Malaysia. Int. J. food Microbiol. 33: 183-194.

Scott, E. (1996): Foodborne diseases and other hygiene issues in the home. J. Appl. Bacteriol., 80: 5-9.

Uyttendaele, M.R.; Debevere, J.M.; Lips, R.M. and Neyts, K.D. (1998): Prevalence of Salmonella in poultry carcass and their products in Belgium. Int. J. Food Microbiol., 40: 1-8.

Velge, P.; Cloeckeart, A. and Barrow, P. (2005): Emergence of salmonella epidemics:the problem related to Salmonella enterica serotype Enteritidis and multiple antibiotic resistance in other major serotypes. Veterinary Res., 36: 267-288.
Weal, F.; Ahmed, A.T. and Dalia, K. (2011): Egg Packagers Exposure to Salmonella Enteritidis in Egyptian Laying Farms. Research Journal of Animal and Veterinary Sciences, 5: 1-5.

Wray, C.; Davies, R.H. and Corkish, J.D. (1996): Enterobacteriaceae. In: poultry diseases, Jordan, T.W., M. Patison (Eds). $4^{\text {th }}$ Edn., B. saunders, Philadelphia, PA, USA., pp: 9-43.

Wafaa, A.; Soumaya, S.A and Hatem, M.E. (2012): A Survey on Salmonella Species Isolated from Chicken Flocks in Egypt. Asian Journal of Animal and veterinary Advances 7(6): 489-501.

\footnotetext{
مدى تواجد ميكروب السالمونيلا فى الاجاج المبرد فى محلات مدينة بورسعيد

نهله طـله قرثسى ، جيهان محمد عمر محمد

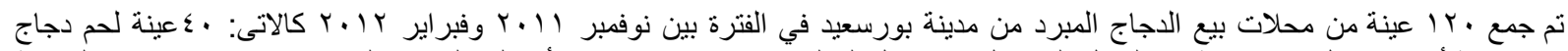

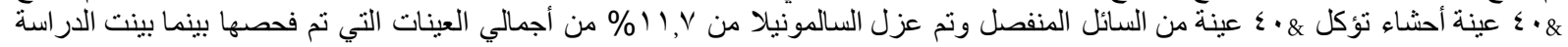

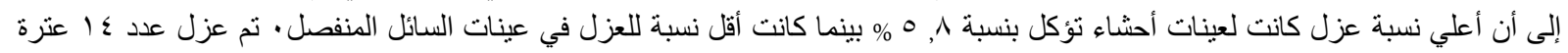

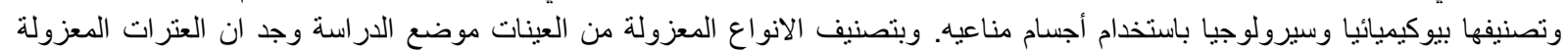

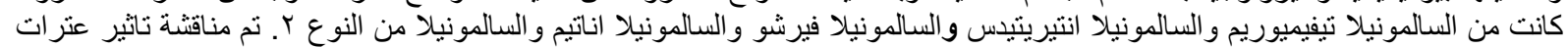

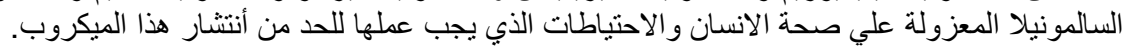

